E International

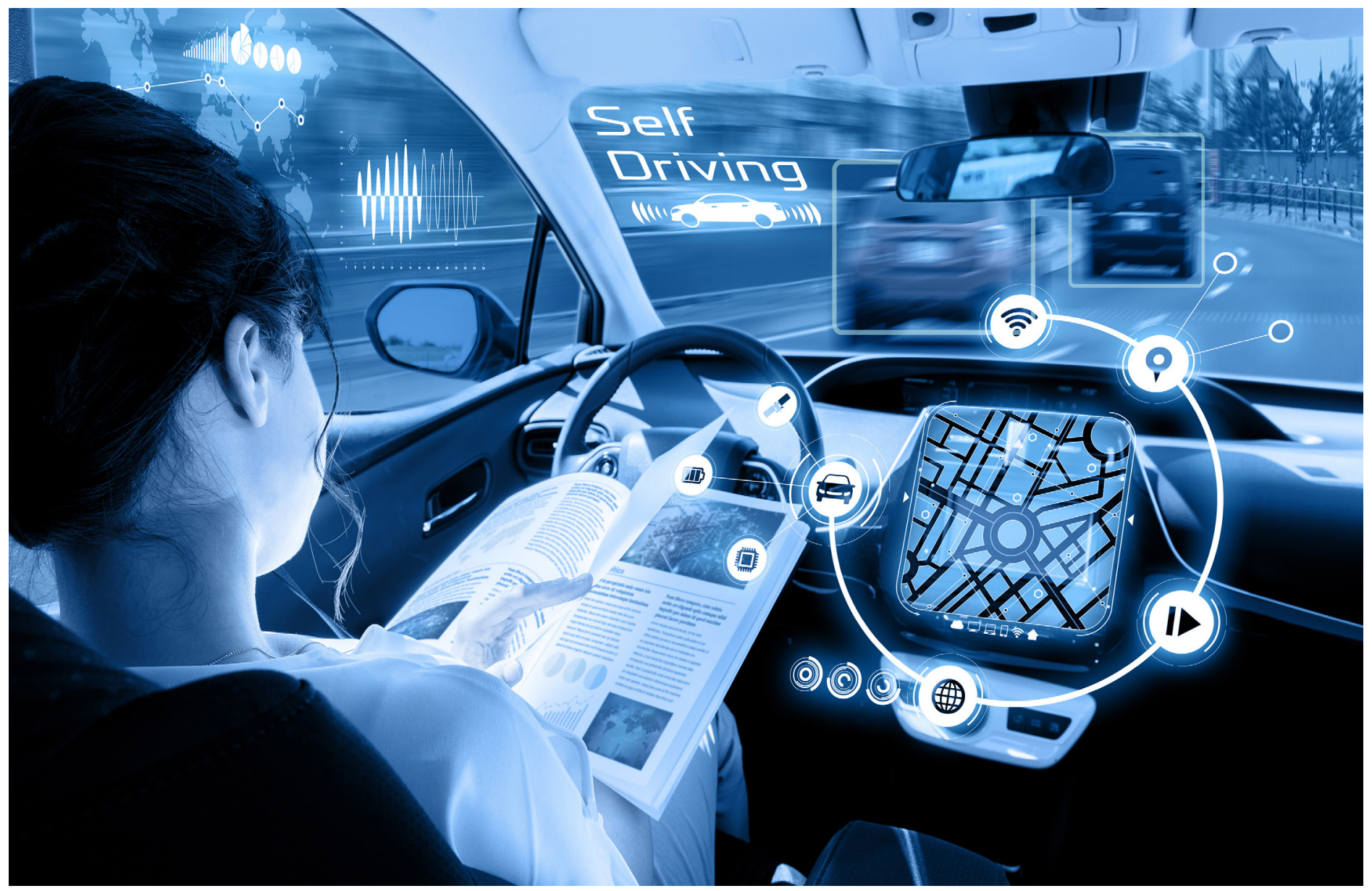

\title{
The Influence of
} Technologies and Lifestyle on the Value of Time

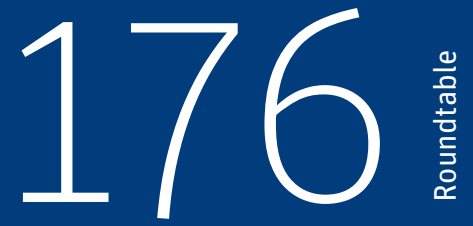

Discussion Paper

Phil Goodwin

University of the West of England, 


\section{The Influence of Technologies and Lifestyle on the Value of Time Discussion Paper}

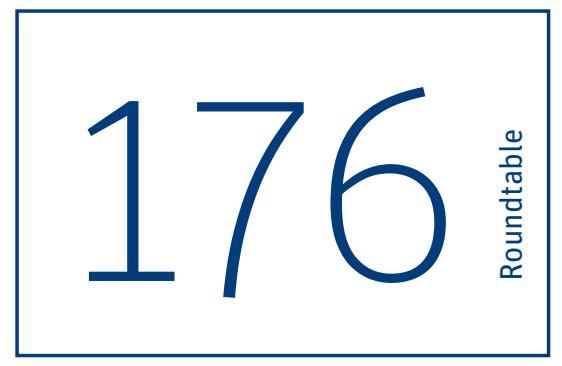

Phil Goodwin

University of the West of England, Bristol 


\title{
The International Transport Forum
}

The International Transport Forum is an intergovernmental organisation with 59 member countries. It acts as a think tank for transport policy and organises the Annual Summit of transport ministers. ITF is the only global body that covers all transport modes. The ITF is politically autonomous and administratively integrated with the OECD.

The ITF works for transport policies that improve peoples' lives. Our mission is to foster a deeper understanding of the role of transport in economic growth, environmental sustainability and social inclusion and to raise the public profile of transport policy.

The ITF organises global dialogue for better transport. We act as a platform for discussion and prenegotiation of policy issues across all transport modes. We analyse trends, share knowledge and promote exchange among transport decision-makers and civil society. The ITF's Annual Summit is the world's largest gathering of transport ministers and the leading global platform for dialogue on transport policy.

The Members of the Forum are: Albania, Armenia, Argentina, Australia, Austria, Azerbaijan, Belarus, Belgium, Bosnia and Herzegovina, Bulgaria, Canada, Chile, China (People's Republic of), Croatia, Czech Republic, Denmark, Estonia, Finland, France, Former Yugoslav Republic of Macedonia, Georgia, Germany, Greece, Hungary, Iceland, India, Ireland, Israel, Italy, Japan, Kazakhstan, Korea, Latvia, Liechtenstein, Lithuania, Luxembourg, Malta, Mexico, Republic of Moldova, Montenegro, Morocco, the Netherlands, New Zealand, Norway, Poland, Portugal, Romania, Russian Federation, Serbia, Slovak Republic, Slovenia, Spain, Sweden, Switzerland, Turkey, Ukraine, the United Arab Emirates, the United Kingdom and the United States.

\author{
International Transport Forum \\ 2 rue André Pascal \\ F-75775 Paris Cedex 16 \\ contact@itf-oecd.org \\ www.itf-oecd.org
}

\section{ITF Discussion Papers}

ITF Discussion Papers make economic research, commissioned or carried out in-house at ITF, available to researchers and practitioners. They describe preliminary results or research in progress by the author(s) and are published to stimulate discussion on a broad range of issues on which the ITF works. Any findings, interpretations and conclusions expressed herein are those of the authors and do not necessarily reflect the views of the International Transport Forum or the OECD. Neither the OECD, ITF nor the authors guarantee the accuracy of any data or other information contained in this publication and accept no responsibility whatsoever for any consequence of their use. This document and any map included herein are without prejudice to the status of or sovereignty over any territory, to the delimitation of international frontiers and boundaries and to the name of any territory, city or area. Comments on Discussion Papers are welcome.

Cite this work as: Goodwin, P. (2019), "The Influence of Technologies and Lifestyle on the Value of Time", International Transport Forum Discussion Papers, No. 2019/03, OECD Publishing, Paris. 


\section{Table of contents}

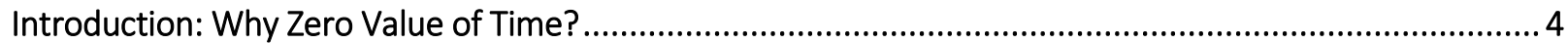

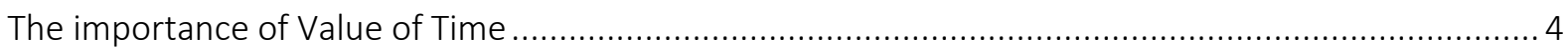

Seven ways that this importance may have been overstated .............................................................. 5

The evolution of Roundtables on the Value of Time ..................................................................... 7

Theoretical and practical research on an estimation of time-saving:

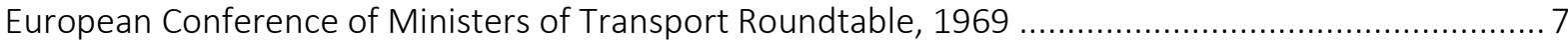

Value of Time: European Conference of Ministers of Transport Roundtable, 1976 .......................... 10

Time and Transport: European Conference of Ministers of Transport Roundtable, 2003 .................12

Young people: Travel, socioeconomic explanations, and hypotheses for values of time........................... 14

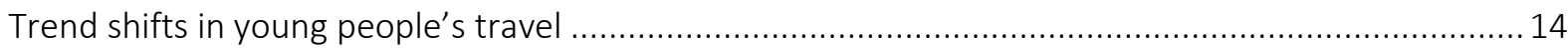

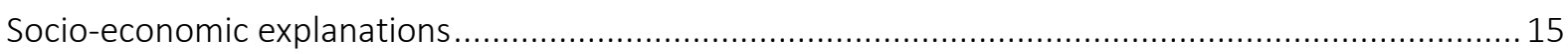

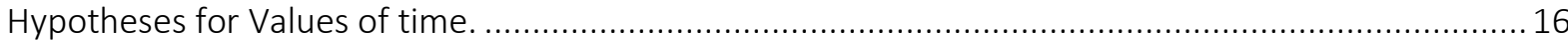

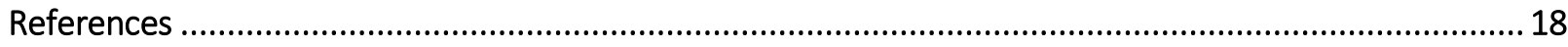




\section{Introduction: Why Zero Value of Time?}

The title of this Roundtable reflects widespread concerns that too much emphasis may be given to the importance of speed in determining travellers' choices, and in judging the value for money of public investments. Technical and social change are in some cases reducing the apparent Value of Time savings by making travel more convenient, more comfortable, or by providing the opportunity to undertake useful economic activity or pleasurable social activity. In other cases there are considerations which may be more important than speed, such as the improvement of health by spending time on active travel modes notably walking and cycling, and environmental benefits including energy conservation and the reduction of harmful emissions. There are cases where travel time savings get used for more or longer distance travel, or get converted into wider effects on land use or non-travel activity, which can make the link between initial speed increases and final costs and benefits complex, sometimes affecting the estimated value and nearly always changing the incidence of who benefits and who loses. Even the interpretation of 'Value of Time' is difficult, since it can actually be telling us more about the different value of money for richer and poorer groups. The overall effect of these factors suggests that we should put less attention on the value of travel time savings, through speed increases.

Although these issues have come to the fore due to the rapid change in social and economic trends, and the technologies of transport and communication, they are in general not new issues. This is the fourth Roundtable on values of time organised by the International Transport Forum (ITF) and its predecessor, the European Conference of Ministers of Transport (ECMT) and nearly all of these issues have been discussed from the earliest days, though not always resolved. A review of three earlier Roundtables, in 1969, 1976 and 2003 identifies continuing attention to these themes, from the point of view of explaining choices, appraising investments, and assessing equity. Some important conclusions from this earlier work may have to be relearned.

There have recently been substantial shifts in the trends of travel behavioural choices, notably affecting orientation to car use by younger age groups, and at the other extreme the effects of longer life expectancy, both moderated by area of residence, the nature of employment contracts, security and migration. Each of these will in turn have affected indicators like Value of Time, raising issues of equity as well as forecasting, and potentially very different impacts in the short and long term. Hypotheses below are suggested for the likely effects on values of time, and how they should be used.

\section{The importance of Value of Time}

At face value "Zero Value of Time" seems to make a suggestion that travel time savings should not be given a monetary value. It is therefore necessary to start the paper by considering what this means and why it is relevant.

Attribution of a monetary value to time spent travelling or, more precisely, the value of travel time savings (VTTS) has been important for two different though connected applications.

\section{Value of Time as a parameter that helps to estimate behavioural choices}

People are assumed to gain a benefit from spending less time on travel so they can spend more time on some other more beneficial activity. In situations where to travel faster will cost more money, there is a 
trade-off to be made between the time spent on different travel activities and the money cost. Knowledge of this trade-off should help to explain, and therefore predict, choices between different modes, destinations, routes, times of day, and frequency of making trips, as calculated in the most reliable and available behavioural choice models.

\section{Value of Time as a parameter that helps to determine value for money in allocation of public funds}

There may be an economic benefit to society as a whole by reducing the time spent travelling, either from the sum total of the individual benefits made by individuals, or by enabling greater economic productivity. If so, then it will be worth investing economic resources in improved (essentially, faster) transport services in order to deliver a greater economic benefit, as calculated in the most reliable available methods of social cost-benefit analysis.

These two related calculations both require a unit which has dimensions of money per unit of time (for example, pence/minute, euros/hour, etc.). There is a substantial volume of empirical and theoretical research which produces such parameters, in great detail, for very many different types of people and activities and circumstances, and their application results in estimated benefits, to individuals or the economy as a whole, of huge sums of imputed value, typically by far the greatest element of the calculated benefits. This central concept, spending more money in order to travel faster, has been a dominant feature of the formal methods of prediction and appraisal.

\section{Seven ways that this importance may have been overstated}

Considering the above, an increasingly critical view that the benefits calculated in this way may give too much weight to 'time' as compared with other criteria of importance to individuals and objectives of transport policy has grown in recent years. Not all these suggestions are consistent with each other, and some have been controversial and discussed energetically. Without implying judgement on the merits of the arguments, the following counter suggestions have been raised:

1. Time is not as overwhelmingly influential in individual travel decisions as has been thought. Comfort, convenience, noise levels, air quality, opportunity for exercise, access to telecommunication signals and the conditions to use them, social status, desire for variety, desire for habitual reassurance, enjoyment of company or conversely privacy, conditions suitable for undertaking productive work or private enjoyment during travel, access to refreshments and toilets, and many other factors affect choices. By putting too much emphasis on duration, and not enough on the other factors, there will be too much emphasis on speed, and predictions of behaviour will be inaccurate.

2. There is evidence that the overall time spent travelling changes little as a result of faster travel in some analyses but not in all. People do not 'save time' so much as use that 'some' or all of that time to travel more frequently or to more distant destinations. There may well be benefits of doing so in a different format, but there may also be costs, for example by reduced accessibility for some due to consequential land use changes, and by the generation of extra traffic which in general erodes, or in certain extreme circumstances outweighs the intended time savings. The eventual gainers will not necessarily be the same people at all as those whose hours of time 
saving were assessed in an appraisal: the initial advantages to them will have an effect, for example, of changing land prices, resulting in a shift of benefit between travellers and landowners. In the limit, this argument suggests that there is no reduction in the time spent travelling and it is therefore misleading to value the benefit in units of time.

3. The Value of Time is not a simple single measure of benefit, but a ratio of two quantities, the marginal utility of time and the marginal utility of money. It is not credible to assume that the utility of time is different for everybody, but that the utility of money is the same for everybody. Therefore when we estimate a Value of Time we have to cross-examine the context, to assess whether what we are detecting is simply that some people have more money than others, or consider it of less importance. If time and money are interchangeable currencies (as is implied in the phrase 'Value of Time'), the distributional impacts of an initiative would have to take account of both.

4. There are some travel activities whose benefits are greater the longer is spent on them (within limits). This especially relates to the health benefits of active travel notably walking and cycling, but can also apply to that category of travel where the experience of travel (e.g. sightseeing) is the benefit sought. In these circumstances simply reducing the time spent will not be an advantage. Walkers and cyclists may well choose to take a longer, slower route specifically to spend more time on them, and tourists will not want to pay more for a briefer tour.

5. Similarly, some train journeys particularly are suitable for working by using on-line connectivity or suitable tables, power sources, lighting and ride comfort. Those who do this often (including some academics) find that there are discrete amount of time which can be usefully spent on marking scripts or writing papers for conferences. An hour or more may be useful, but less doesn't give sufficient time for focus. In these circumstances arriving at your destination earlier is not a benefit, and can be irritating. The same argument is increasingly being offered if autonomous vehicles offer the opportunity of other activities while travelling by car without needing to drive.

6. Some transport improvements are specifically addressed to higher standards of comfort. A feature of the interaction between comfort and speed is that empirical work has found that less comfortable travel, other things being equal, has higher values of time (that is, people are prepared to spend more money to save an hour of uncomfortable travel than comfortable travel). Therefore one of the effects of higher comfort is to lower the Value of Time savings. One can say that achieving a lower Value of Time is a mark of the success of such improvements. Therefore a progressive reduction in the Value of Time, achieved in this way, is a mark of progress.

7. There is an additional problem that the now widespread use of stated preference methods, based on hypothetical experiments using formal controlled variation in alternatives specifically defined by their time and money costs, makes it too easy for the analysts to persuade themselves that they have eliminated (often expressed as 'taken account of') other complicating factors This seems to make it possible to deduce well-defined trade-offs in the experiment, but in conditions which do not correspond with the more complex interweaving of multiple considerations in real life. The outcome can be to produce estimates with high quality statistical performance and low quality behavioural reality: the simulation, by its specification, is bound to accord a significance to travel times whether or not that mirrors the real decision. 
This list should not be taken as implying uncritical acceptance of all the points. In each case there has been an argument, and mostly a defence offered to defend orthodox practice. The defence has in turn been criticised, and a more or less permanent debate ensues. But the important point is that, taken as a whole, there is a shift in mood about travel choices and transport appraisals.

Put simply, there is a widespread current of opinion that too much emphasis has been put on speed, and not enough on other policy objectives, and this is reducing the reliability of forecasts and the value for money of investments.

Hence, in a rather exaggerated way, the phrase 'Zero Value of Time' is helpful. It reflects a mood that a progressive reduction in the Value of Time can be a mark of success, or a mark of more realistic understanding of what is important, or both. Achieved reductions in the Value of Time can be interpreted as a measure of the benefits from improving the conditions of travel.

In this context it is not axiomatic that the main research task is to encourage an everlasting process of more and more detailed calculations of values of time separated by types of individual and context and mode and location and duration and size and alternatives available for the use of the time saved. This may not be helpful if it ignores this bigger questions of what are values of time for, and what do they mean? Since a large part of the agenda of this Roundtable is devoted to precisely such calculations, it is necessary to assess them in the context of the wider question: why are we doing this?

This is not primarily a theoretical argument, but a practical one: what is the relative importance of time as compared with health, comfort, reliability, air quality, energy conservation and climate change? What do we do with the detailed results to be discussed at the Roundtable?

\section{The evolution of Roundtables on the Value of Time}

None of the issues raised in the above arguments for downgrading the importance of values of time, and the items on the agenda for the current one, are completely new. These points have been discussed at Roundtables of the International Transport Forum (ITF) and its predecessor, the European Conference of Ministers of Transport (ECMT) and form part of an international literature of considerable size on the subject dating back to the 1960s, with precursors even as far back as the 1930s. A full historical literature review is beyond the scope of this paper, but it is useful to give a summary of how some of the seven aspects listed above, seen as steps towards a consideration of Zero Value of Time, have been treated in three earlier Roundtables at the ITF.

\section{Theoretical and practical research on an estimation of time-saving: European Conference of Ministers of Transport Roundtable, 1969}

A single introductory report on Value of Time was produced by Harrison and Quarmby (1969) of the United Kingdom Ministry of Transport for a Roundtable nearly 50 years ago. Together with a closely related advisory note issued by the Ministry (McIntosh and Quarmby, 1970), these documents gave an overview of all the theoretical, empirical and practical information available at that time. They tackled 
the widest range of issues of principle and practice, and potentially created the agenda for subsequent Government practice in the United Kingdom and many other countries. It should therefore be considered one of the most influential of all the Roundtable reports, though its importance, from the age before internet citations, is not now realised. In the direct quotations below, readers may appreciate the clarity and style of its language, which is a model of scientific writing.

Among the many topics, four are still particularly relevant to the issues discussed above.

\section{Values of time only usefully derive from choice if the choices are realistic}

The authors argued

"When travellers make choices... they may well not be making a conscious trade-off between time and money; indeed there are usually very many other factors that both consciously and unconsciously affect their choices. For the researcher intent upon estimating a value of travel time, there is a danger in principle in trying too hard to find a value of time in situations where time or cost may not be important variables at all. All of this points to the need to approach the analysis of a choice situation with the primary object of trying to explain the choice, rather than trying to derive a value of time. If a value of time emerges from the explanation of choice - then the effort is rewarded: if it does not, then nothing can be gained by twisting the explanatory relationship so as to yield a time value"

Comment: This was written before stated preference methods became common (although some early versions were cited). The problem now they are nearly universal is that the experimental design appears to have solved the problem of complicating factors, by scrupulously removing or controlling for them. This does not solve the underlying problem. If the respondents' real experience is of choices whose critical influences are not the controlled variables in the study, they may well give 'true' answers to the questions as stated. The framing makes it almost impossible not to reveal a Value of Time, and these answers may give values whose statistical diagnostics are extremely good. But there must be a serious question about their reliability for forecasting real world choices where those complicating aspects inevitably reassert their importance. This underlines the point that, in a sense, stated preference methods are 'too easy' in investigating many new segments of people or time. The straw, however, remains straw, not gold.

\section{Other important variables, not themselves measured in units of time, are nevertheless experienced over time, and will affect the estimated values}

The authors argue

\footnotetext{
"Time saving" is a composite entity taking on different attributes in different situations - freedom from irritation at delays, freedom from physical effort, from overcrowding. Reduction in the lengths of time that have to be devoted to enduring these various conditions may be accounted valuable in themselves even though no explicit consideration is given to expanding a traveller's range of activities, and hence 'saving time' may be valued, even though the savings are not seen in any way as productive"
}

Comment: Here there is a problem. If the attributes of different modes, say, are inherently and permanently linked to travel using them, it may be reasonable to increase or reduce the value of the time spent travelling to allow for discomfort and so on. But this inherent link is rarely the case, and never 
in the long run. Consider the discomfort of uncomfortable seats on buses. It would be a distortion of policy to focus all the attention on increasing the speed of the buses, so the discomfort can be endured for a shorter period: it may be more sensible to look at changes in design to make the seats more comfortable. Where the Value of Time is modified by such other considerations, the resulting value has nothing useful to say about the effects of improving the conditions, and may indeed give exactly the wrong signal. Attributes which are not unchangeably associated with duration should, as far as possible, be the subject of separate investigation looking at their own importance and how to improve them. The quote above should be considered a temporary phase in the study of Value of Time, not a permanent principle. This in turn underlines the implication that a reduction in the Value of Time spent travelling may be treated as providing benefit analogous to a reduction in the duration of travel. This is rarely done. Some promoters of investments to increase speed resist research that seems to lead to lower values of time, for fear that this will undermine the cost-benefit case for their scheme, but that would not be a legitimate or necessary argument.

\section{So called Values of Time are in part (or totally) measures of the value of money}

Harrison and Quarmby (1969) were very much more explicit about the problem of the marginal utility of money than most other authors since. The following quotation raises profound and still unsolved problems.

"... all empirical studies have shown that the rich are more inclined to pay to save time than the poor. Some very familiar economic arguments suggest that this observed fact should not be accepted normatively. Consideration of the usual proposition about the declining disutility of money or, less abstractly, notions of equity or a more desirable distribution of income, would suggest that some counter-weighting should be employed".

This was a particular problem to the argument that behavioural (observed) values of time should be used as the empirical base in appraisal of the value of money for public investments (which, other things being equal, is the natural desire of many economists):

"... it is the method itself which has inherent income distribution implications... The issue is particularly acute since, by their very nature, cost benefit appraised investments are not paid for directly by beneficiaries, hence employment of this basis of evaluation will tend to shift investment towards the richer sections of the community, without any compensating increase in payments from them. Thus, by normal criteria, the distribution of income will be worsened"

Comment: This elegant and clear argument failed to have the same influence on practice, in terms of systematic adjustment to the values of time is a way discussed in the next section. But it has been normal that at least in valuing non-working time, some form of 'equity' average Value of Time has been used. However, the more different values are accorded to different population segments or activity types, the more the issue will arise again: to what extent are we actually measuring not the utilities of time saving, but the utilities of saving money correlated with the segmentation chosen? This is discussed further below.

On the very last page of the report of Roundtable, in the section summarising the discussions, a brief comment made is directly related to the discussions at our own Roundtable:

"Research has so far failed to differentiate sufficiently between social groups, yet these imply differences in occupational and housing mobility, attitude to disutility of travel, etc. This particularly applies to the study of manual workers' evaluation of time." 
The comment about manual workers probably referred to some discomfort that the empirical studies to date had been excessively focussed on office workers and professionals. However, the point is a wider one, and it is interesting that this one sentence has taken nearly half a century to find its way as a key objective of the current Roundtable.

\section{Value of Time: European Conference of Ministers of Transport Roundtable, 1976}

Findings of this Roundtable also culminated in a single introductory report, by Goodwin (1976). It is clear that it never acquired the same influential effect as the Roundtable report by Harrison and Quarmby, but readers may forgive me if I make a brief summary of two of its relevant points, since I was the author of the report and some of its recommendations deal with unresolved issues which are still, in my view, relevant to our discussions.

\section{The reciprocal of the Value of Time}

The report built on a distinction made by Harrison and Quarmby (1969) between what later came to be called 'generalised cost' and 'generalised time', in a way which radically re-interprets the information content of the Value of Time and changes its use in appraisal. The author proposed:

"It is argued that what is sometimes interested as a value of time should more properly be regarded as a utility of money... Behavioural values of time can be used to provide distributional weights for money costs and benefits"

The suggestion arises from development of the idea of combining time and money (and, sometimes, other similar costs, though that is ignored here) into a single overall measure of cost which as far as possible represents the whole disutility spent on travel. There were two main formulations, generalised cost and generalised time. Exactly the same information is included in both.

$$
\begin{gathered}
G(m)=M+v T, \text { and } \\
G(t)=T+M / v
\end{gathered}
$$

Hence where $G(m)$ is generalised cost measured in units of money, $M$ is the money cost, and $T$ is the time cost multiplied by $v$, the Value of Time, to convert it into money units. $G(t)$, by contrast, is generalised cost measured in time units (sometimes called generalised time), and the money $M$ is converted into time units by multiplying it by the reciprocal of the Value of Time.

The Value of Time itself is the ratio of the marginal utility of money and the marginal utility of time, and the two ways of using it - the value to convert time into equivalent money, or its reciprocal to convert money into equivalent time - are of identical status in terms of the empirical origin.

However, since the estimated Value of Time increases with income, the two formulations have different effects. Generalised cost implies that over the long term, as general income rises, there will be an increase in the perceived cost of travel, due to the rise in the value of the time component. Generalised time, on the other hand, will tend to decrease in the long term, due to the reduction of the value of the money component.

The argument, in summary, suggested that generalised time was likely to be more useful than the generalised cost, because it represents a more fundamental currency, notionally available equally to everybody, not subject to inflation, exchange rates, money markets, or arbitrary devaluation. Hence it 
followed that the so-called 'Value of Time' could more realistically be interpreted as measuring the declining marginal utility of money as income rises. Instead of using the empirical results to say that time savings were more valuable to one group than another, we would be able to say that money costs, or savings, were less valuable to one group than another. The Value of Time in use would not be a weight to attribute greater effect to the values of time for one group than another, but less weight to the money value of the same groups. The UK Ministry of Finance, the Treasury, has for many years recommended that income related weights should be used to assess the distributional consequences of policies where equity is an issue, but it is possible this has never been applied in practice in transport applications, by the reciprocal of the Value of Time or indeed other sources.

Comment: A constant marginal utility of money, and a constant marginal utility of time, are two extreme cases, but extending the idea to the more general case, one would make the hypothesis that the utility of money is sensitive to the amount of (available) money people have, and the utility of time is sensitive to the amount of (available) time that people have. As they approach the constraint of their money budget, estimated values of time will fall, and as they approach the constraint of their time budget, estimated values of time should increase - provided the two are not correlated. The implications may be considered by Table 1 below, representing the effects of the interaction between the marginal utility of time and money.

Table 1. Hypothesis for the effects of available time and available money on Value of Time

\begin{tabular}{|c|c|c|}
\hline & Time Poor & Time Rich \\
\hline Money Poor & $\begin{array}{l}\text { - A low-income employed single parent } \\
\text { with little time or money. } \\
\text { - Utility of time high and utility of money } \\
\text { high. } \\
\text { - True Value of Time indeterminate, but } \\
\text { would be credited with low Value of } \\
\text { Time in usual method. }\end{array}$ & $\begin{array}{l}\text { - A retired pensioner on a state } \\
\text { pension, plenty of time but little } \\
\text { money. } \\
\text { - Low utility of time savings, high } \\
\text { utility of money savings. } \\
\text { - Revealed Value of Time low. }\end{array}$ \\
\hline Money Rich & $\begin{array}{l}\text { - A high income entrepreneur working all } \\
\text { the hours of the week and receiving a } \\
\text { large income. } \\
\text { - Low utility of money savings, high utility } \\
\text { of time savings. } \\
\text { - Revealed Value of Time high. }\end{array}$ & $\begin{array}{l}\text { - A retired person with a very high } \\
\text { personal pension and much } \\
\text { leisure. } \\
\text { - Low utility of time savings, low } \\
\text { utility of time savings. } \\
\text { - True Value of Time indeterminate, } \\
\text { but would be credited with high } \\
\text { Value of Time in usual method. }\end{array}$ \\
\hline
\end{tabular}

The example deliberately takes extreme cases to make the point, and reveals that if we do not take account of differences in the utility of money (due to income) and the utility of time (due to lifestyle), then two groups seem to be treated particularly unfairly, the low income person with no time, and the high income person with plenty of time. The other two groups will also have a biased calculation, but the broad comparison is understandable. 


\section{The treatment of housework}

The author proposed that the

"Time spent on travel associated with housework should be valued as working time rather than leisure time"

Comment: This proposition derived from a rather simple argument that housework was a productive activity with an economic value, and therefore should be accorded the higher value of 'work' time than the lower value of 'leisure' time. Since there was not a well-defined market relationship in the way in which housework was allocated and done, it would be necessary to use imputed values from the markets for child care, cleaners, cooks and other providers of similar services. The suggestion was treated rather dismissively in the report of discussion, using language of 'feminine pursuits' that would not really be thought helpful today. But it raises a bigger question, as in the previous example. Some housework, especially by employed parents, is done in conditions of high time-pressure and low income, and is clearly of economic significance. It would be misleading to interpret the lower willingness to pay for time savings due to low incomes, as though it demonstrated lower utilities or social productivity.

It is appreciated that this approach differs from the received wisdom that distributional consequences, invariably focussing on money, are outside the realm of economic analysis and should be left to politicians. It does however fit well into the idea that distributional consequences, for example of initiatives like road user charging cannot be assessed purely in terms of the effects of money flows to different income groups, but should take into account the resulting effects on time (and other) impacts of the surrounding policy changes, as argued by Anable and Goodwin (2018) in the latest ITF Report on the subject.

\section{Time and Transport: European Conference of Ministers of Transport Roundtable, 2003}

This Roundtable was not specifically on the Value of Time, but more broadly on the importance of time considerations in transport, and therefore two of its papers (by Deardoff on International trade and Tavassy and Bruzelius on freight) are not considered further here.

\section{Socio-economic factors}

The paper 'Time and Passenger Transport' by Crozet (2003) reflected on some of the earlier concerns, albeit extending them into new areas including discounting, and congestion charging. Crozet argued that

"The value of time, which symbolises the monetary value placed on time by individuals, is therefore the product of a process of simplification. As such it theoretically depends upon individual social economic factors such as wealth, income, socio-professional category, reason for trip, mode, etc."

This reinforces the suggestion for distinguishing the values of those factors in estimation.

\section{Stability of Travel Time}

There was also a substantial discussion of a new issue raised by Zahavi (1974), on the implications of empirical stability in the total amount of time spent travelling, and a concern also with the observation that 
"The desire for speed increases commensurately with the increase in the value of time, which itself is closely linked to higher incomes"

This was one of the reasons for paying more attention to differences between different social groups.

It is worth noting that Kopp (2003) very firmly dismissed the constant travel time discussion in the summary of the roundtable discussion:

"The presumption of a fixed-time budget has led to concerns that time savings achieved by transport policy actions are partly undone by the reactions of travellers, with negative consequences for the environment. The Roundtable assessed the evidence indicating that the hypothesis of constant travel time budgets is difficult to maintain. Travel time evaluations should not proceed from an assumption of constancy of time budget. Forecasts of travel demand based on this assumption tend to underestimate the net benefits of transport policies".

Comment: This is perhaps an unusually firm conclusion from the type of discussion typical at Roundtables, though I am not sure whether it accurately reflected the discussion. If it did, then it should be said that it does not entirely represent what happened in research and policy advice subsequently.

The empirical observation that total time spent travelling, while not absolutely constant, nevertheless does show a remarkable degree of stability and has been affirmed in many studies since, through substantial literature including Metz (2010) and others.

The interpretation of its significance on benefits has also changed. Probably the most important contention is that if travel time is constant, it is because the initial benefits of time savings are used for more or further travel. A softer version of the hypothesis, that some of the travel time savings are used for more travel, is surely now almost universally accepted, being one of the ways in which 'induced traffic' appears. This additional travel will have both benefits and disbenefits, reducing the intended relief from congestion and increasing energy use and emissions. They must be taken into account. On the other hand, there are often claimed to be wider economic benefits, which will be reflected in changes in land values and activity outside the transport sector. These should also be identified. One contention is that while the time savings may indeed be converted into different types of benefit, the value of the time savings still gives the simplest way of measuring the value of these other benefits, which in a perfect market will be sustained through subsequent stages. 


\section{Young people: Travel, socioeconomic explanations, and hypotheses for values of time}

In recent years there has been interest in a reduction in the propensity of young people to use cars, observed in many countries, but with special features in each. In the United Kingdom this tendency had first been observed in 2005, and appeared to have started over a decade earlier though had not been noticed at the time. Since 1945, the baby-boomer generation has been considered as highly car oriented, acquisition of license and car being considered as a rite of passage into adulthood.

Taking into account the discussions above about influences and interpretations of the Value of Time, this section takes a recent major study in the United Kingdom of what appears as a substantial shift in the travel choices and behaviour, and their explanations which do not, in general, give substantial weight to considerations of the Value of Time. The changes are so big, however, that they should have implications for the Value of Time, and potentially interesting further research, so some possible hypotheses are developed.

The study, by a team of researchers from the Universities of the West of England, and Oxford, was commissioned by the United Kingdom Department for Transport (DfT). Its report, by Chatterjee et al. (2018) available online, contains many tables and figures and a detailed analysis of both cross section and longitudinal data, with a particular focus on the quasi-dynamic method of following cohorts of young people and their travel choices from the age of 17 into their forties and in some cases fifties.

Below is a summary of the main observed trends, and the explanations which seemed most consistent with the data. Then some conclusions are suggested which would affect values of time.

\section{Trend shifts in young people's travel}

A shift in trends concerning young people's travel appears to have occurred in early 1990. It was noticed strongly in the United Kingdom, and to some extent in some but not all other developed economies. Since then, total trips by young people have been reducing, and most of that reduction is accounted by a fall in car trips, drivers and passengers. Public transport trips have actually increased, both absolutely and as a mode share, though not by a large amount.

The proportion of young people having a driving license fell from $48 \%$ down to $29 \%$ of the traditional entry age, and $75 \%$ down to $63 \%$ for people in their twenties. There was a similar fall in the proportion having access to a household car.

The fall affected both men and women, but the turning point was later for women: the period of 'peak driver licence' was around 1990 for young men, and later, about 2000 for young women. Since then the trend has been downwards for both, with some year by year variation. The significant feature of this fall was that for nearly everybody, the probability of having a licence continued monotonically to increase as they get older, but for each successive cohort that growth was at a lower level. So while the proportion holding licences grew for every cohort, the overall proportion holding a licence fell. This may have settled down in the most recent figures we had, for people born in the 1990s. By the end of the period the young women had nearly converged on the young men, but the older women had not. 
When looking at the car miles driven, as with licenses, each successive cohort has been at a lower level, though there is no sign of a settling down in the most recent period. So far we have only had 20-25 years observations since the turning point, and there is not yet any indication of an acceleration to catch up with earlier cohorts, as there would be if the shift were solely a delay rather than a reduction in car use.

As a result, for young men each cohort has successively less car use up to the age of about 50, but it is the opposite for men over the age of 50, whose car use is still increasing cohort by cohort. For women, there is a similar picture, but the numbers are smaller and the curves closer together. It is as though the fifties are now the boundary between youth and age.

An important related phenomenon is that the later you learn to drive, the less you drive when you do start. This seems to cut across all age groups, including those who started driving decades ago, before the trend reversal. There must be some self-selection here, but also possibly an effect that travel habits set up in the early years have a lasting effect.

\section{Socio-economic explanations}

The next stage in the project was to explain why this all happened. This looked both at changes in transport, and also demographics, living situation, socio-economic situation, communications technologies, values and attitudes, and wider mobility. The methods included theoretical and empirical literature reviews, studies of trends, and analysis of available data, but not new empirical studies.

In summary, the evidence indicates that the causes of the changes in young people's travel behaviour do not in the main stem from changes in the transport services available to them. They have been driven by changes in young people's socio-economic situations (increased higher education participation, rise of lower paid, less secure jobs and decline in disposable income). At the same time young people have been moving into long-term employment later and becoming parents later. Closely tied to these changes there has been a decline in home ownership and an increase in urban living.

There is less strong evidence but it seems likely that changes in young people's social interactions (substituting face-to-face interaction with digital communication) and changes in the importance that people attach to driving have also been significant.

It is important to be clear that the influences relate to long-term changes that predate the (2007-8) global economic crisis and subsequent recession.

Considering the implications for the future, there are few signs that these causal factors are due for a large scale reversal. There does not seem to be a high probability of a decline in the gig economy, structural changes in the labour market leading to a return of full term, secure employment. There are no suggestions for substantially reducing participation in higher education, or moving people in massive numbers out of the cities into distant suburbs. The age of childbearing seems unlikely to reverse. We know that disposable immediate income will be under pressure from the need to fund pensions and social care. There are some calls for a massive redistribution of wealth and income back from old to young, but no consensus or substantial policies to do so.

There is evidence that changes by new drivers in their teens and twenties are still having an effect into their thirties and forties. In the limit that would imply that in the whole population the baby boomers and their successors are progressively replaced by the millennials and their predecessors, an uncompleted process now about a third of the way through. 


\section{Hypotheses for Values of time}

It should be said that no research was carried out into values of time during this study, either as a potential cause for the changes or as possible results of them. There were no strong indications that these were important salient issues. So the conclusions are necessarily tentative. But the following points are suggested for discussion.

- There has been no strong tradition that 'age' is a mainstream segmentation variable for behavioural analysis especially related to transport forecasting and appraisal. It has been of subordinate interest: few forecasting models treat age as a key input. Yet the shift in travel behaviour is so strong, and its potential long term implications so great, that we have to take seriously how central age as a variable, and aging as a process, has been. Therefore there is a strong case for recommending that age should become a primary segmentation variable in its own right, treated longitudinally with systematic changes as people get older. It will be noticed that the effects cannot be captured by successive cross section surveys: age has to be considered in terms of the aging process. This should be applied to future Value of Time studies. It will be useful to distinguish age as a segmentation variable, and check its stability over time. We have nothing to show that this will be important, but every reason to expect that it may be.

- Some of the changes observed are definitely connected to income - not as measured by indicators like national average GDP, but the specific income effects of employment trends and the changing distribution as between older and younger generations which have been so prominent. In these cases close attention to the effects of income on the marginal utility of money will prove to be important, and as argued above may have a bigger effect on estimated values of time than is usually considered.

- However, changes in the conditions of work do also affect the availability of usable spare time and variation over the day or week (as well as the higher incidence of unemployment). Thus we are likely to observe a significant proportion of the younger age groups with changes in both the marginal utility of cost changes and the marginal utility of time changes, where the effect on estimated values of time is ambiguous and needs very careful scrutiny to avoid misleading conclusions.

- Correlated factors have been greater incidence of the importance of urban living, rented accommodation, and higher education. Each of these can have material effects on the cost and time of travel, and the quality of alternative activities. Values of time may be a suitable instrument for seeking insight on these.

- Finally we note the very rapid changes in the use of telecommunication technologies, which have a variety of quite distinct possible effects on the Value of Time: reduction in the uncertainty of mode and route choice, potential for useful or interesting activities on line while travelling, and a potential substitute for travel. The evidence base on these questions is sometimes contradictory, 
possibly because there are simultaneous effects in contrary directions, some more strongly affecting one group and others affecting other groups.

Therefore there are potentially rich insights to be obtained from studies of this sort. But it should be mentioned that exactly the same caveats apply to the generation of large numbers of estimated values of time here, as in the other controversial questions discussed. The questions of what do they mean, and how are they to be used, still have to be addressed. 


\section{References}

Anable, J. and P. Goodwin (2018), Assessing the Net Overall Distributive Effect of a Congestion Charge" available at: https://www.oecd-ilibrary.org/transport/assessing-the-net-overall-distributive-effect-of-acongestion-charge $7 f 4 c 51 f 2-e n$

Kopp, A (2003), Summary and Conclusion in Time and Transport Roundtable, report number 127, European Conference of Ministers of Transport, pp.97-115, OECD, Paris.

Chatterjee K. et al. (2018), Young people's travel - What's changed and why? Review and analysis. Project Report. Department for Transport, http://eprints.uwe.ac.uk/34640

Crozet Y. (2003), Time and Passenger Transport in Time and Transport Roundtable report number 127, European Conference of Ministers of Transport, pp. 25-65, OECD, Paris.

Goodwin P. (1976), Value of Time, Roundtable report number 30, European Conference of Ministers of Transport OECD Paris

Harrison, A.J. and D.A. Quarmby (1969), Theoretical and Practical Research on an Estimation of Timesaving: Roundtable 6, European Conference of Ministers of Transport, OECD, Paris.

Mackie, P., R. Batley and T. Worsley (2018), Valuing transport investments based on travel time savingsa response to David Metz. Case Studies on Transport Policy. ISSN 2213-624X

McIntosh, P.T. and D.A. Quarmby (1970), Generalised Cost and the Estimation of Movement Cost and Benefit in Transport Planning, MAU Note 179. Department of the Environment, London

Metz, D. (2010), Saturation of demand for daily travel, Transport Reviews 30 (5) 659-674

Metz, D. (2018), Valuing transport investments based on travel time saving: inconsistency with United Kingdom policy objectives, Case studies on transport policy.

SACTRA (1999), Transport and the Economy, Standing Advisory Committee on Trunk Road Appraisal, Department for Transport, London

Zahavi Y. (1974), Travel time budgets and mobility in urban areas, US Department of Transportation, Washington, May 


\section{EInternational Transport Forum}

\section{The Influence of Technologies and Lifestyle on the Value of Time}

This paper looks at the roles of technologies and other factors in lifestyle choices, travel patterns and behaviours. Building on earlier Roundtable reports on value of time, it discusses how recent behavioural changes might affect the disutility of time spent travelling relative to time spent on other activities. The paper concludes with a discussion on the implications for policy practitioners around modelling and assessing value of travel time savings.

All resources from the Roundtable on Regulating App-Based Mobility Services are available at:

www.itf-oecd.org/zero-value-time-roundtable 